\title{
Опыт разработки термостойкого, радиационно-стойкого и водородостойкого оптического волокна
}

И. С. Азанова ${ }^{7}$ azanova@pnppk.rи, Д. И. Шевцов, О. Л. Вохмянина', И. Д. Саранова ${ }^{7}$ А. Н. Смирнова, М. И. Булатов Е. А. Поспелова ', Ю. О.Шаронова' , Т. В. Димакова, П. Ф. Кашайкин ${ }^{2}$, А. Л. Томашук², А. Ф. Косолапов ${ }^{2}$, С. Л. Семёнов ${ }^{2}$

1 ПАО «Пермская научно-производственная приборостроительная компания", Пермь, Россия

2 Научный центр волоконной оптики РАН, Москва, Россия

Разработана технология изготовления, освоено серийное производство и проведены испытания оптического волокна с кварцевой сердцевиной стойкого к повышенным температурам, ионизирующему излучению и водородосодержащей среде. Такие оптические волокна могут быть использованы в кабелях для специальных систем телеметрии, бортовых кабелях авиакосмической техники, геофизических кабелях для измерения температуры в скважине.

Ключевые слова: оптическое волокно, ионизирующее излучение, повышенная температура, водородосодержащая среда

\section{Experience of the Development of Heat-resistant, Radiation-resistant and Hydro-resistant Optical Fibre}

\section{I.S.Azanova', azanova@pnppk.ru, D. I.Shevtsov', O.L.Vokhmyanina', I. D.Saranova', A. N.Smirnova', M. I. Bulatov 1, E. A. Pospeloval, Yu. O. Sharonova', T. V.Dimakova', P. F. Kashaykin², A. L. Tomashuk², A. F. Kosolapov², S. L. Semenov² \\ " PJSC "Perm Scientific and Production Instrument-Making Company", Perm, Russia \\ 2 Fibre Optics Research Centre of RAS, Moscow, Russia}

The manufacturing technology of pure-silica-core optical fibre mass production has been developed and mastered. Research for its resistance to elevated temperatures, ionizing radiation and hydrogen-containing medium was conducted. These optical fibres can be used in cables for special telemetry systems, on-board cables for aerospace engineering, and geophysical cables for measuring temperature in a borehole.

Keywords: optical fibre, ionizing radiation, high temperature, hydrogen environment

\footnotetext{
* Примечание редактора: Статья рекомендована программным комитетом конференции, проходившей в рамках специализированной выставки лазерной, оптической и оптоэлектронной техники «Фотоника. Мир лазеров и оптики. 2019».
} 


\section{ВВЕДЕНИЕ}

В последние годы появилась потребность в замене импортных оптических волокон для специальных применений, что привело к разработке ряда моделей специальных волокон на ПАО ПНППК, в частности, радиационно-стойкого волокна с сохранением поляризации излучения для волоконно-оптических гироскопов [1-3].

Дальнейшее развитие этой технологии привело к созданию серийного производства нового типа волокна - одномодового оптического волокна с сердцевиной из нелегированного кварцевого стекла ОВ-РСИ125. Основные параметры волокна представлены в таблице. Разработано две модификации с защитным покрытием двух типов - двухслойное акрилатное и полиимидное покрытие с углеродным подслоем. Также доступны модификации с силиконовым и уретанакрилатным покрытиями. Углеродное покрытие применяется для повышения долговременной надежности волокна (рис. 1), оно способствует сохранению прочности при воздействии влаги на поверхность волокна и предотвращает диффузию молекул воды и водорода в сердцевину световода.

В данной статье представлены результаты испытания оптического волокна ОВ-РСИ125 с полиимидным покрытием с углеродным подслоем на воздействие повышенной температуры, герметичность к водородосодержащей среде и различным видам ионизирующего излучения.

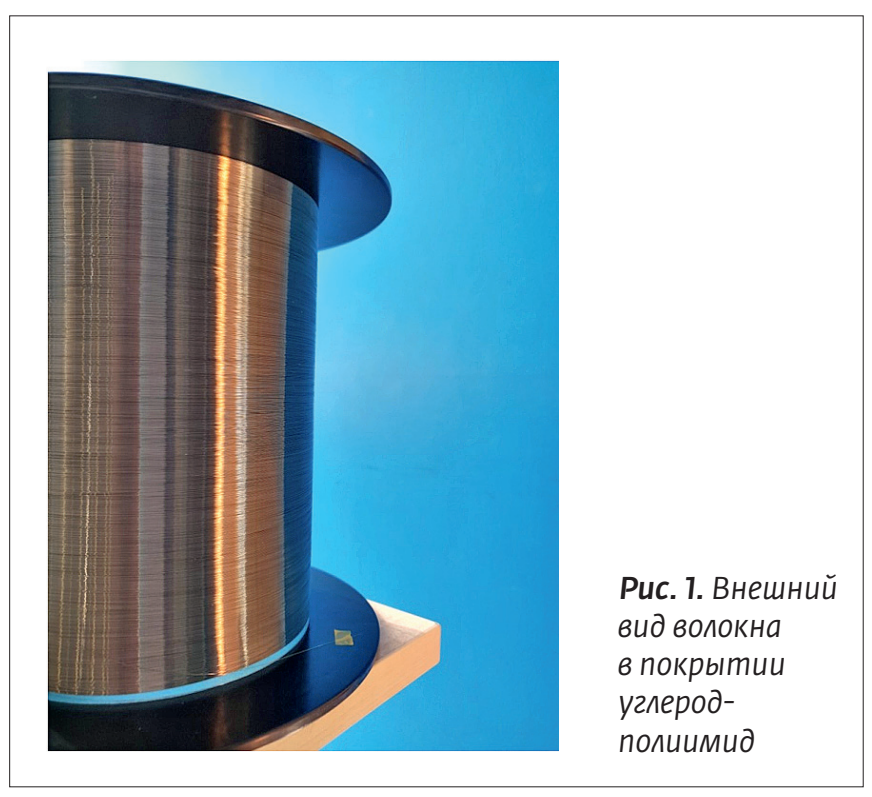

ностью измерения $10^{-5} \mathrm{MBT}$. Оптические потери до и после воздействия измеряли методом обрыва по ГОСТ Р МЭК 60793-1-40-2012.

Результаты испытаний графически представлены на рис. 2. При температуре $300{ }^{\circ} \mathrm{C}$ оптические потери волокна увеличиваются на 0,15 дБ/км и не превышают 0,56 дБ/км. После перехода в нормальные условия оптические потери практически восстанавливаются в исходное состояние.

\section{ИСПЫТАНИЯ \\ НА СТОЙКОСТЬ \\ К ПОВЫШЕННЫМ \\ TEMПЕРАТУРАM}

В процессе температурного воздействия меняются оптические потери оптического волокна. Испытания на стойкость к повышенным температурам проходили следующим образом: оптическое волокно в свободной намотке диаметром 155 мм помещали в термокамеру с погрешностью поддержания температуры $\pm 2{ }^{\circ} \mathrm{C}$ в атмосфере воздуха; температура изменялась ступенчато до $+300{ }^{\circ} \mathrm{C}$, длительность выдержки 8 ч. В процессе воздействия измерялась оптическая мощность на выходе волокна с помощью измерителя мощности с погреш-

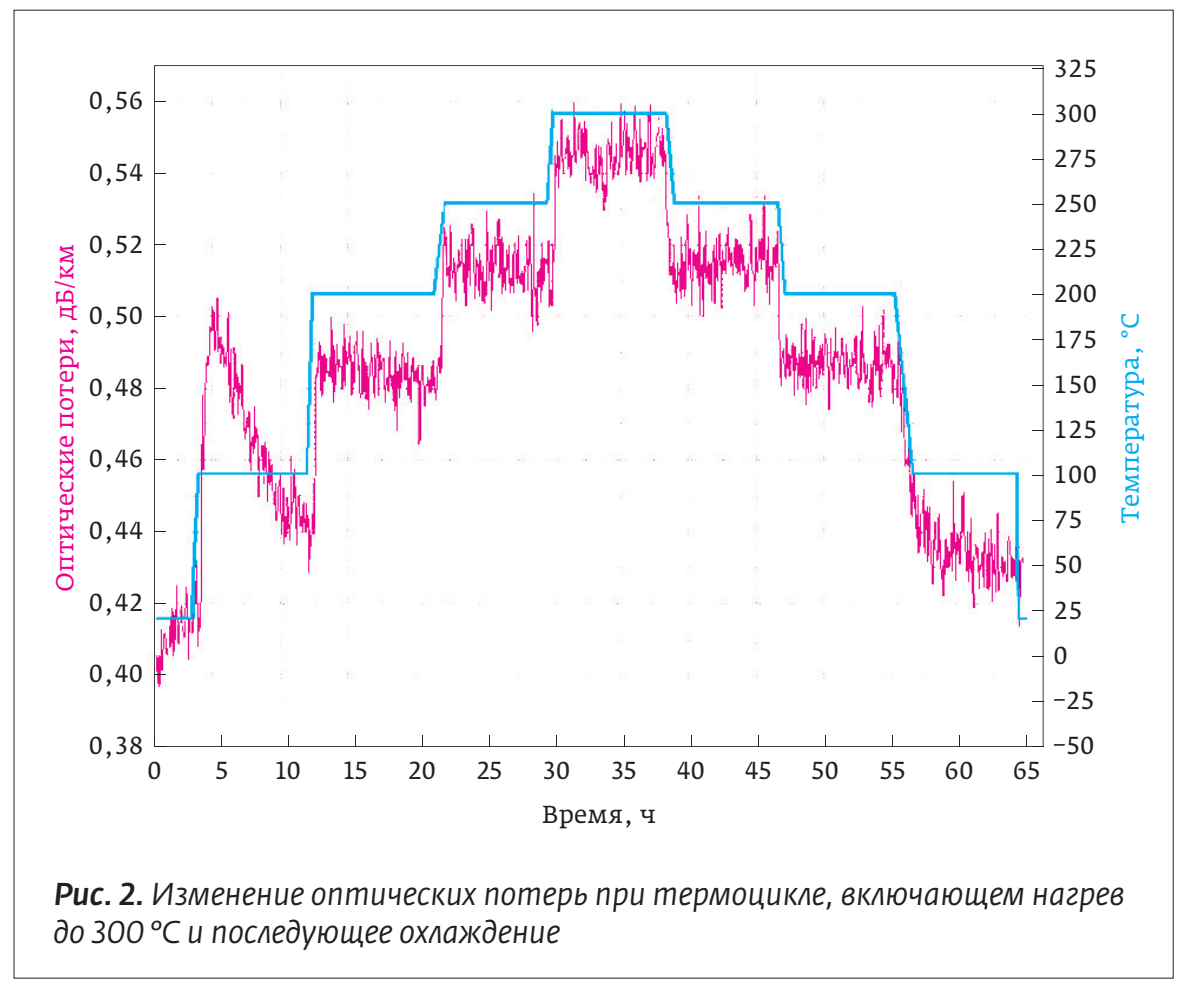




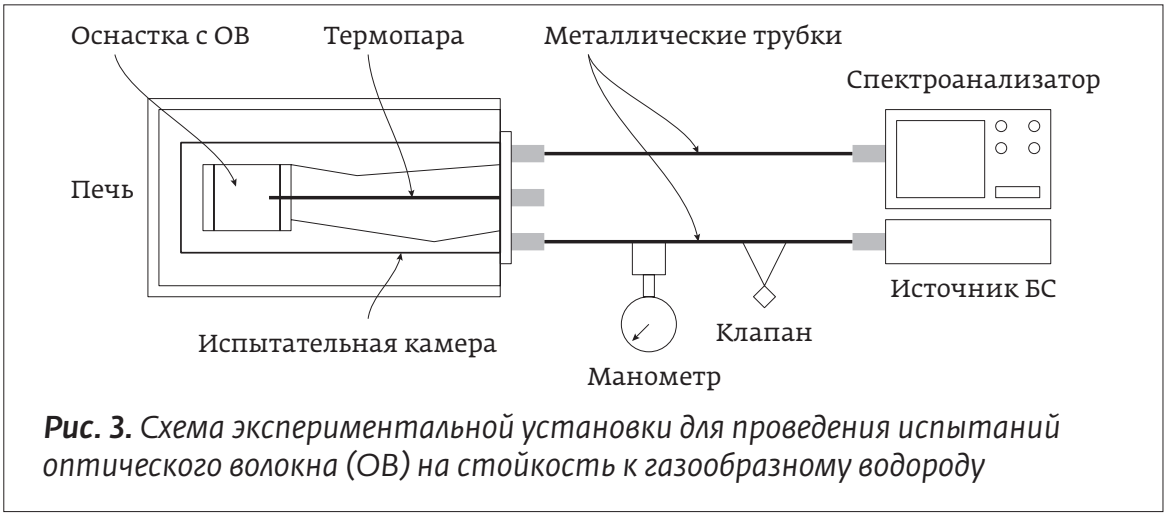

\section{ИСПЫТАНИЯ НА СТОЙКОСТЬ}

\section{К ГАЗООБРАЗНОМУ ВОДОРОДУ}

Испытания оптического волокна на стойкость к газообразному водороду проводились в испытательной камере и сушильном шкафу согласно схеме (рис. 3). В испытательной камере размещались катушки с волокном длиной не менее 200 м, причем оба конца от каждого образца выводились наружу через гермовыводы камеры. Один конец волокна подключался к спектроанализатору для регистрации спектра пропускания волокна, второй конец - к источнику белого света. Камеру проверяют на герметичность и помещают ее в сушильный шкаф, затем в камере создают атмосферу водорода с давлением 10 бар и нагревают до температуры $100{ }^{\circ} \mathrm{C}$. Образцы оптического волокна выдерживали в данных условиях до 40 ч, последовательно измеряя спектр пропускания волокна (рис. 4 a, b). Не зафиксировано изменение спектра пропускания волокна ОВ-РСи125 с углеродполиимидным покрытием (рис. 4, а). В то же время для контрольного образца волокна без углеродного покрытия зафиксировано характерное изменение спектра пропускания на длине волны 1240 нм, что свидетельствует о проникновении молекулярного водорода (рис. 4, b).

\section{ИСПЫТАНИЯ \\ НА СТОЙКОСТЬ К ВОЗДЕЙСТВИЮ ИОНИЗИРУЮЩЕГО}

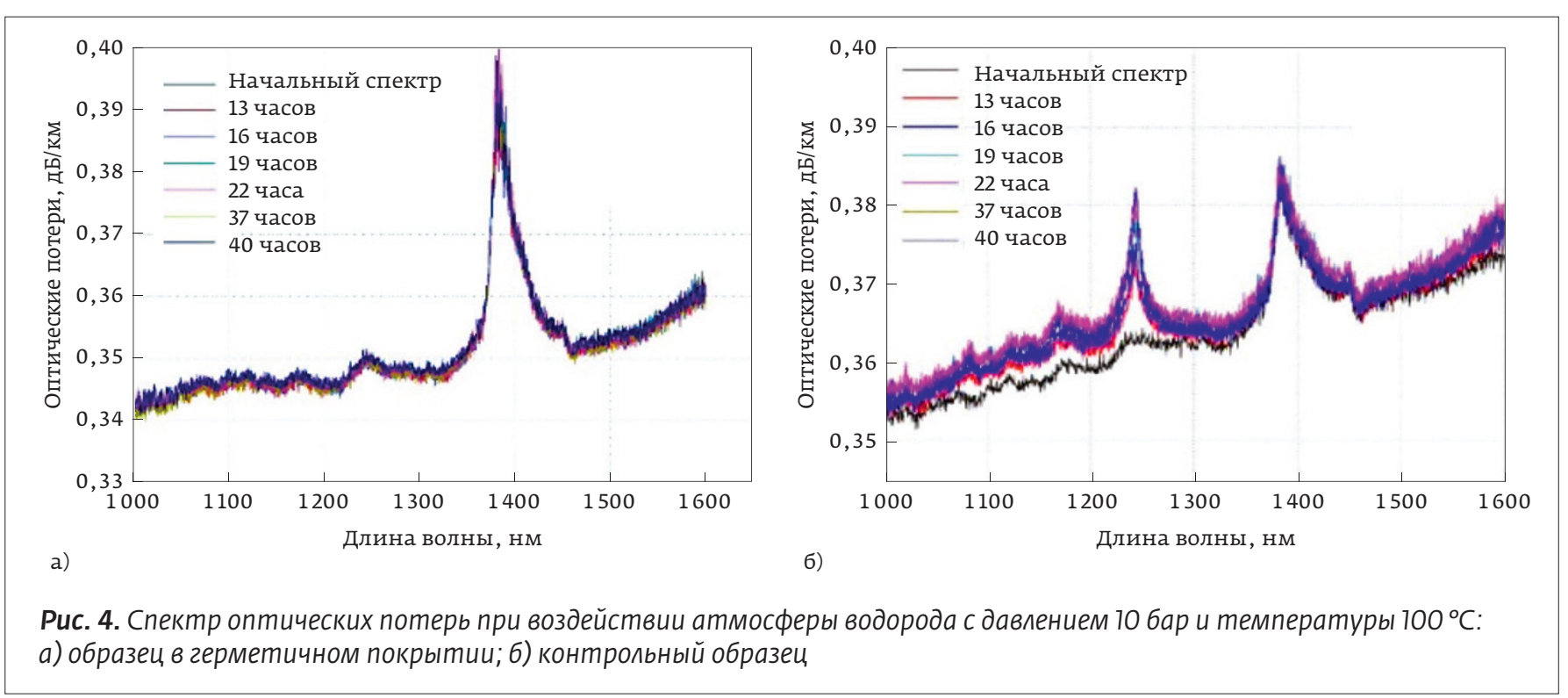

\section{ИЗЛУЧЕНИЯ}

Волокна с сердцевиной из нелегированного кварцевого стекла, как в ОВ-РСИ125, обеспечивают высокую стойкость к воздействию ионизирующего излучения [4]. Радиационно-наведенные оптические потери (РНП) в волокнах с кварцевой сердцевиной существенно меньше, чем у германо-силикатных волокон.

Для исследования реакции оптического волокна на воздействие различных видов ионизирующего излучения была применена методика, основанная на рекомендациях документа ГОСТ РВ 6015-002-2007. Оптическое волокно длиной не менее 100 м испы- $^{-}$ тывалось в свободной намотке для минимизации вклада механических напряжений в РНП. В процессе воздействия регистрировались спектр пропускания волокна, оптическая мощность на рабочих длинах волн (1,31 мкм и 1,55 мкм) на выходе волокна. Также исследовалось влияние вводимой оптической мощности (имитация эксплуатации волокна) на РНП. Образцы волокна помещались в облучательном 


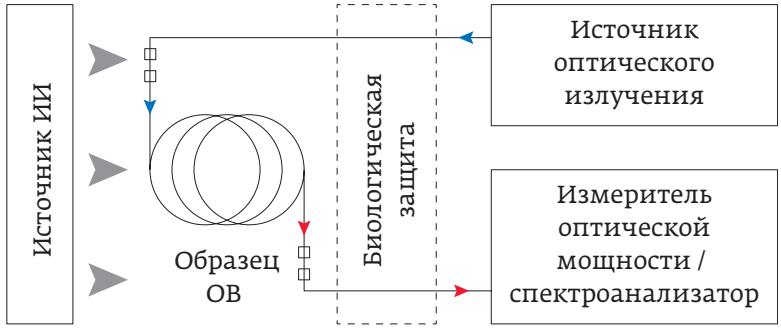

Рис. 5. Схема измерения РНП в образце оптического волокна (ОВ)

зале в область пространства с заданной мощностью дозы ионизирующего излучения, причем имелась возможность изменять температуру образцов непосредственно в этой области. Концы образцов оптического волокна подключались с помощью сварки к оптическому кабелю с таким же волокном, который прокладывался через биологическую защиту и подключался к источнику оптического излучения, измерителю оптической мощности или спектроанализатору (рис. 5).

\section{ИСПЫТАНИЯ НА СТОЙКОСТЬ К ВОЗДЕЙСТВИЮ НЕПРЕРЫВНОГО ГАММА-ИЗЛУЧЕНИЯ}

Исследования проводились с помощью моделирующей установки ГУТ-200М на основе источника гамма излучения ${ }^{60} \mathrm{Co}$. Образец волокна помещался в область с равномерным полем облучения 1 Гр/с или 5 Гр/с.

\section{ИСПЫТАНИЯ ПРИ РАБОТЕ НА РАЗНЫХ ДЛИНАХ ВОЛН}

На рис. 6 представлены РНП на рабочих длинах волн. Для поглощенной дозы до 100 кГр выгодно эксплуатировать данное волокно на длине волны 1,55 мкм из-за существенно меньшего РНП, на начальном

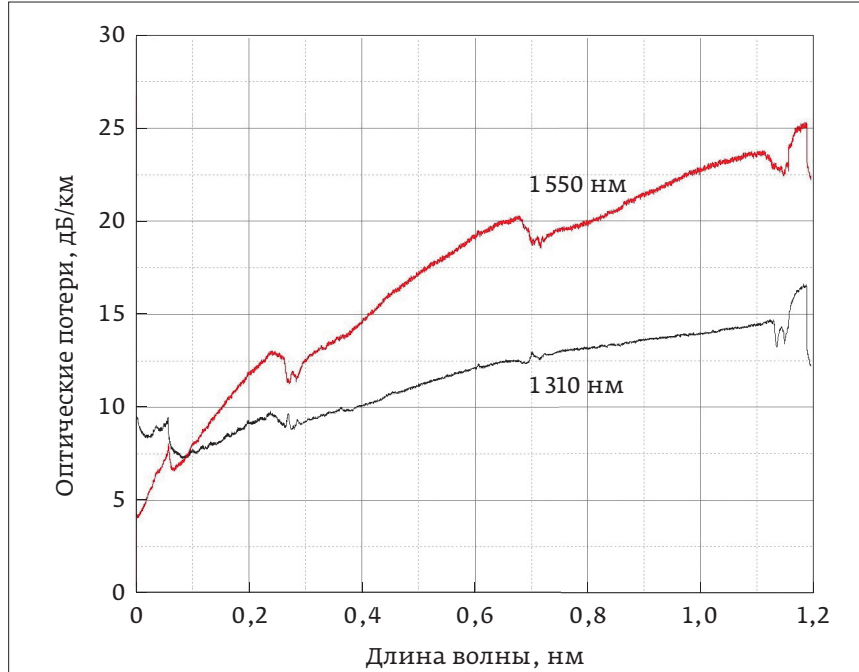

Puc. 6. Радиационно-наведенные потери (РНП) на диине волны 1550 нм (1) и 1310 нм (2) для мощности дозы 5 Гр / с и уровня дозы до 1,2 МГр при воздействии гаммаизлучения $\left({ }^{60} \mathrm{Co}\right)$ при температуре $+30^{\circ} \mathrm{C}$, вводимая оптическая мощность не более $0,1 \mathrm{mkBm}$

этапе облучения разница РНП для длин волн 1,55 мкм и 1,31 мкм составляет до 5 дБ/км. При этом для поглощенной дозы свыше 100 кГр преимущество - за рабочей длиной волны 1,31 мкм, для которой при дозе 1 МГр достигнуты РНП не более 15 дБ/ км. В этом эксперименте вводимая оптическая мощность была менее 0,1 мкВт (для исключения влияния эффекта фотообесцвечивания). При этом необходимо отметить, что РНП для рабочей длины волны $\lambda=1550$ нм более чувствительны к температуре окружающей среды. Во время облучения температура у источника гамма излучения поднималась примерно на $5{ }^{\circ} \mathrm{C}$ и далее принудительной вентиляцией охлаждалась на эти же $5{ }^{\circ} \mathrm{C}$. Можно заметить на участках в районе доз облучения 280 кГр, 700 кГр, 1,1 МГр резкие скачки РНП на величину около 1 дБ/км, связанные с температурой в облучательной комнате.

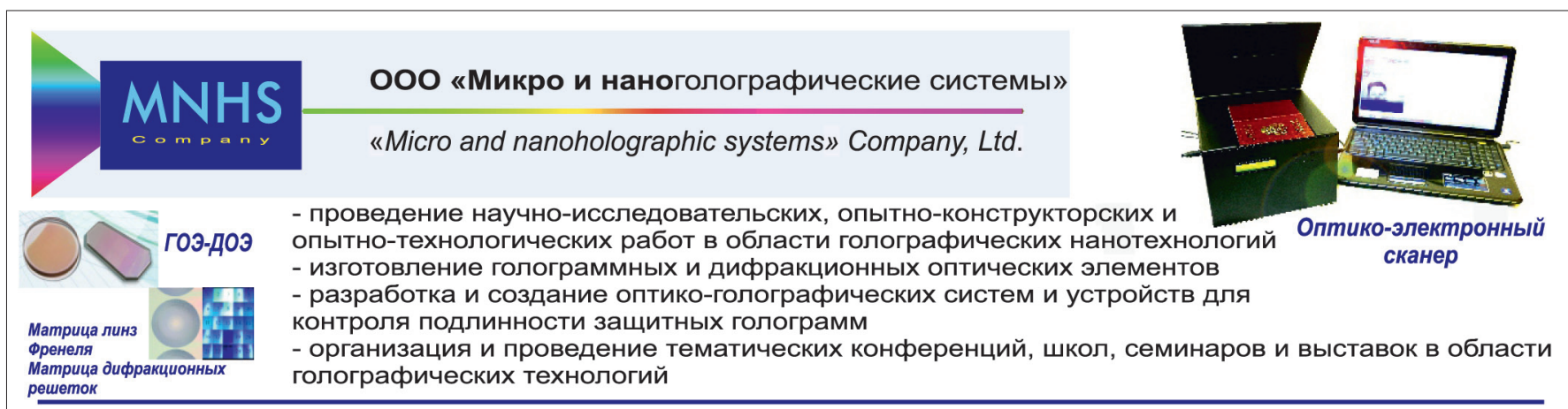

000 «МНГС» РФ,105005, Москва, ул. 2-я Бауманская, д. 5, стр. 1, тел.: +7(499) 263-63-44, e-mail:odinokov@bmstu.ru 


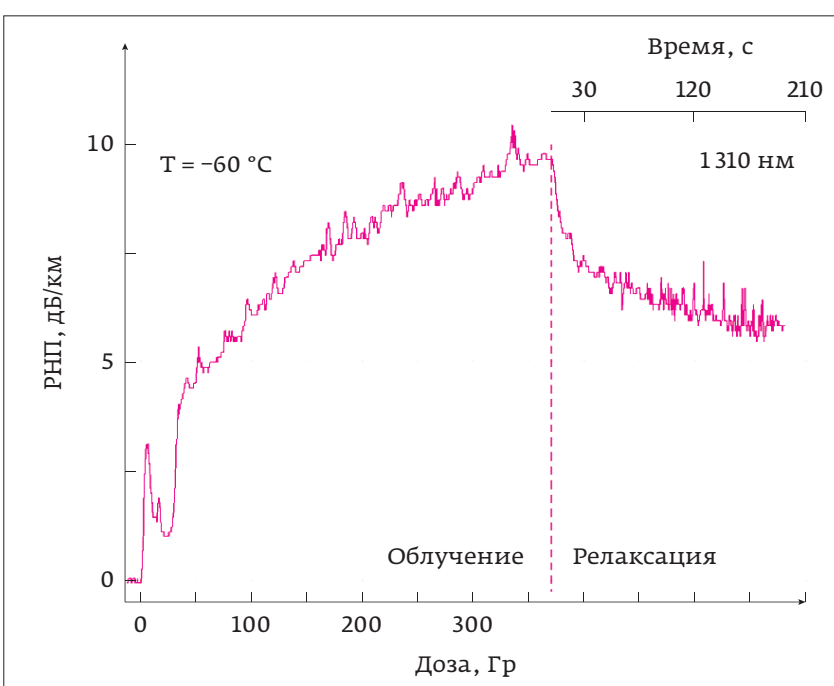

Pис. 7. Радиационно-наведенные потери (РНП) на диине волны 7310 нм при температуре минус $60^{\circ} \mathrm{C}$ для мощности дозы 1,1 Гр/с и уровня дозы 370 Гр при воздействии непрерывного гамма-излучения

\section{ВЛИЯНИЕ ПОНИЖЕННОЙ ТЕМПЕРАТУРЫ СРЕДЫ}

Зависимость РНП от температуры является известным фактом, повышенные температуры положительно влияют на стойкость к ионизирующему излучению. Этот эффект называется термический отжиг. В то же время пониженные температуры значительно ухудшают стойкость оптического волокна [5, 6]. Дефекты сетки стекла, возникающие при воздействии ионизирующего излучения, переходят из возбужденного состояния в промежуточное, находятся в этом состоянии долгое время и далее стремятся к исходному под действием тепловых эффектов. При пониженных температурах переход дефектов сетки стекла из промежуточного состояния в исходное происходит существенно медленнее. [7]. Целью исследования являлась проверка стойкости волокна ОВ-РСИ125 к ионизирующему излучению при пониженной температуре среды минус $60^{\circ} \mathrm{C}$. На рис. 7 представлена зависимость РНП на длине волны 1310 нм от дозы облучения до 370 Гр при температуре минус $60{ }^{\circ} \mathrm{C}$ и вводимой в обра- зец оптической мощности 5 мкВт, а также релаксация в течение 3 минут после отключения источника гамма-излучения. Максимальные РНП при пониженных температурах с поглощенной дозой 370 Гр на образце ОВ-РСИ125 составили 10 дБ/км, что согласуется с данными работы [5].

\section{ВЛИЯНИЕ ФОТООБЕСЦВЕЧИВАНИЯ}

Яркое проявление эффекта фотообесцвечивания можно увидеть в волокне с нелегированной кварцевой сердцевиной [8]. Исследовано влияние вводимой оптической мощности в волокно ОВ-РСИ125 на радиационно-наведенные потери, что крайне важно знать при эксплуатации таких световодов. В четыре одинаковых образца волокна ОВ-РСИ125 была введена оптическая мощность от 6,5 мкВт до 4 мВт на длине волны 1550 нм с помощью оптических аттенюаторов. Волокно облучалось до дозы 1 кГр с мощностью дозы 1,3 Гр/с при температуре $+30^{\circ} \mathrm{C}$.

При увеличении вводимой мощности в тысячу раз удалось снизить потери с 1,9 дБ/км до 1,1 дБ/км при поглощённой дозе 1 кГр только за счет эффекта фотообесцвечивания (рис. 8). При этом зависимость РНП от оптической мощности нелинейная и, с точки зрения эксплуатации, целесообразно вводить не

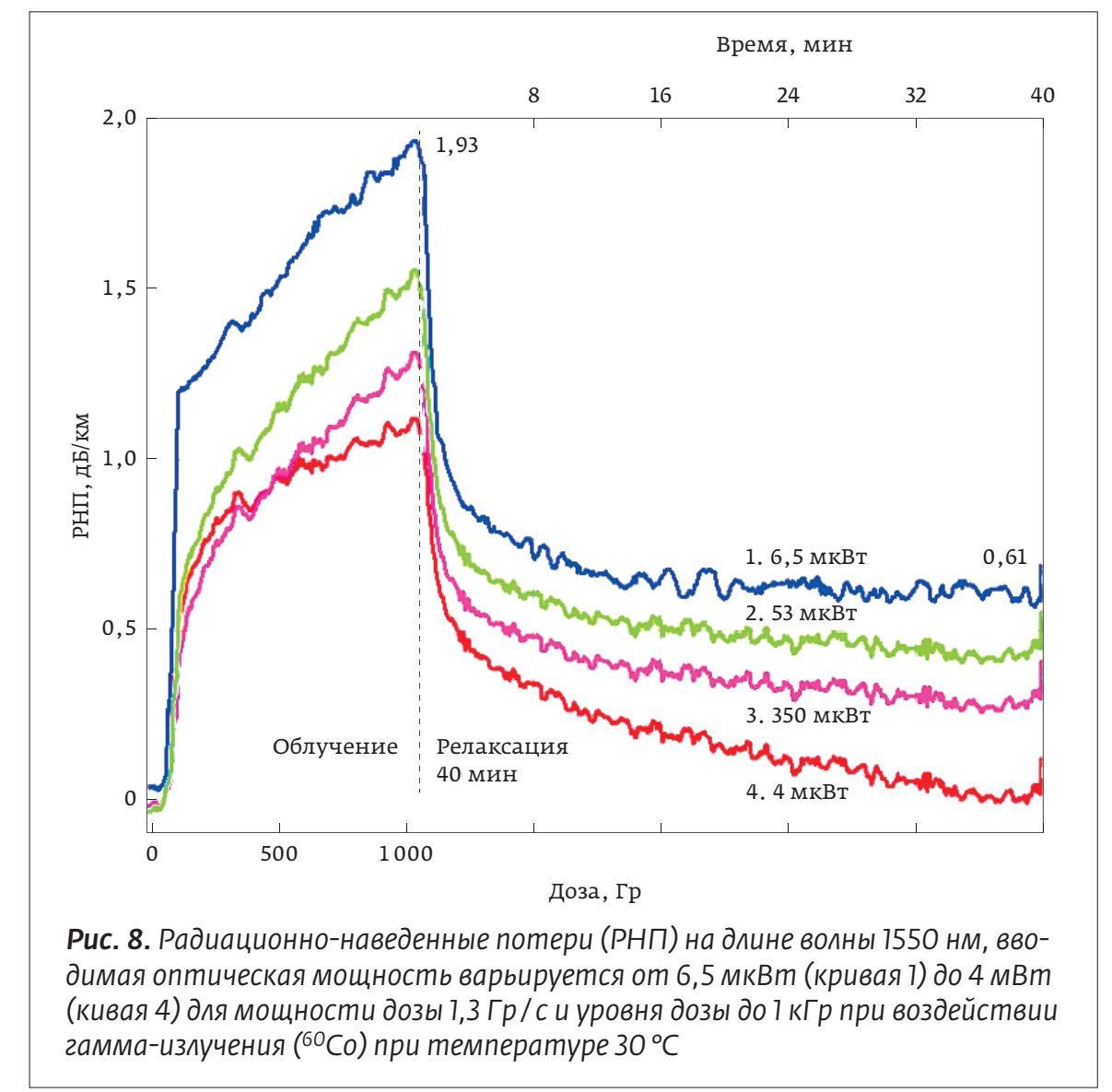




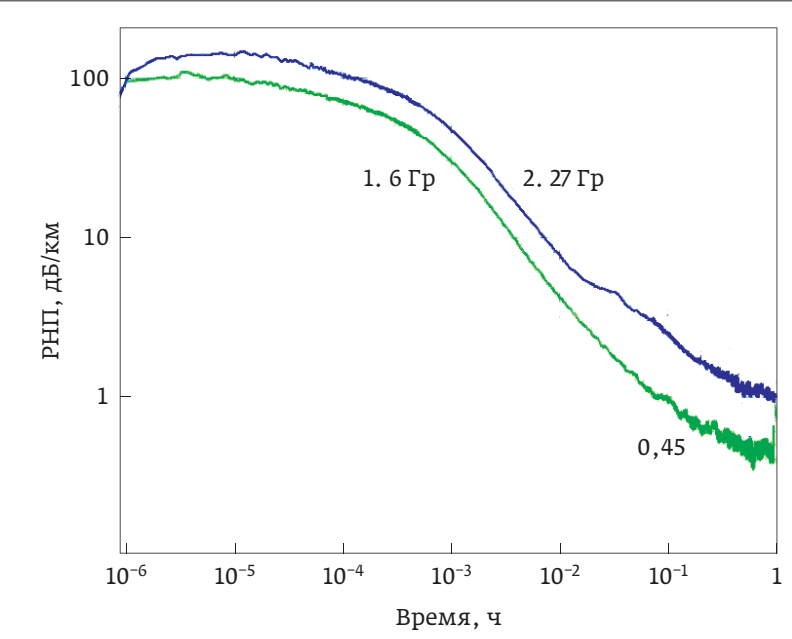

Puc. 9. Радиационно-наведенные потери (РНП) на длине волны 1310 нм после воздействия импульсного гамма излучения длительностью в 20 нс и полученной дозой 6 Гр (1) и 27 Гр (2) за импульс, вводимая оптическая мощность 30 мкВт

менее 1 мВт оптической мощности при указанных дозах. Как показывают исследования [8], эффект проявляется как с непрерывным вводимым лазерным излучением, так и с импульсным.

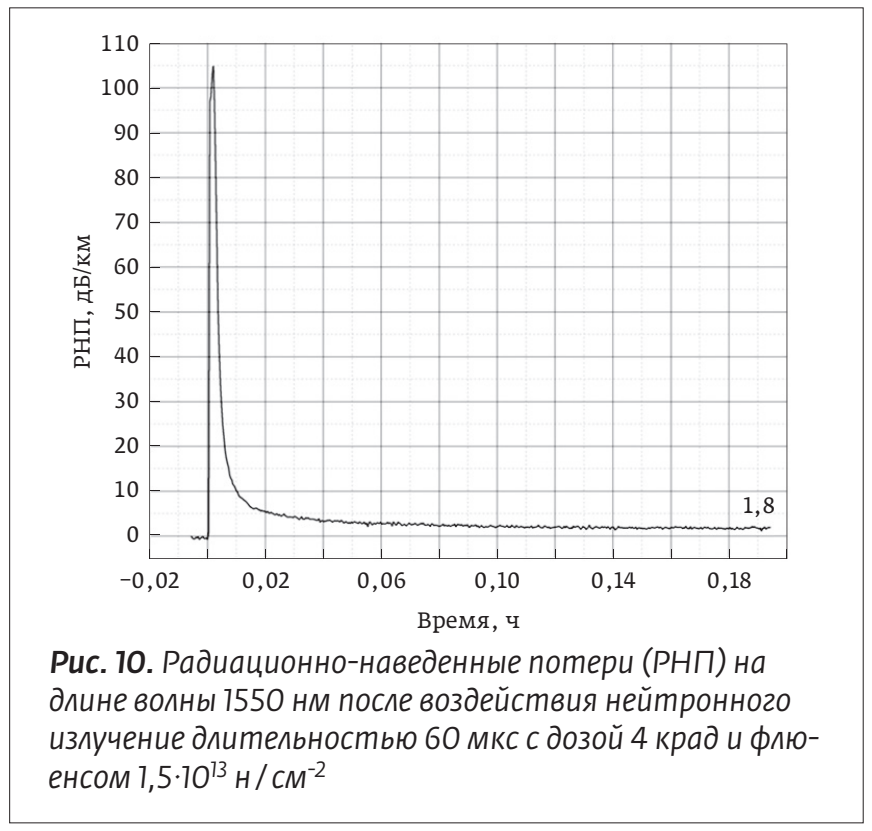

\section{ИССЛЕДОВАНИЯ НА СТОЙКОСТЬ К ВОЗДЕЙСТВИЮ ИМПУЛЬСНОГО ГАММА-ИЗЛУЧЕНИЯ}

Исследования стойкости оптического волокна OB-РСИ125 к воздействию импульсного гамма излучения проходили на импульсном линейном индук-

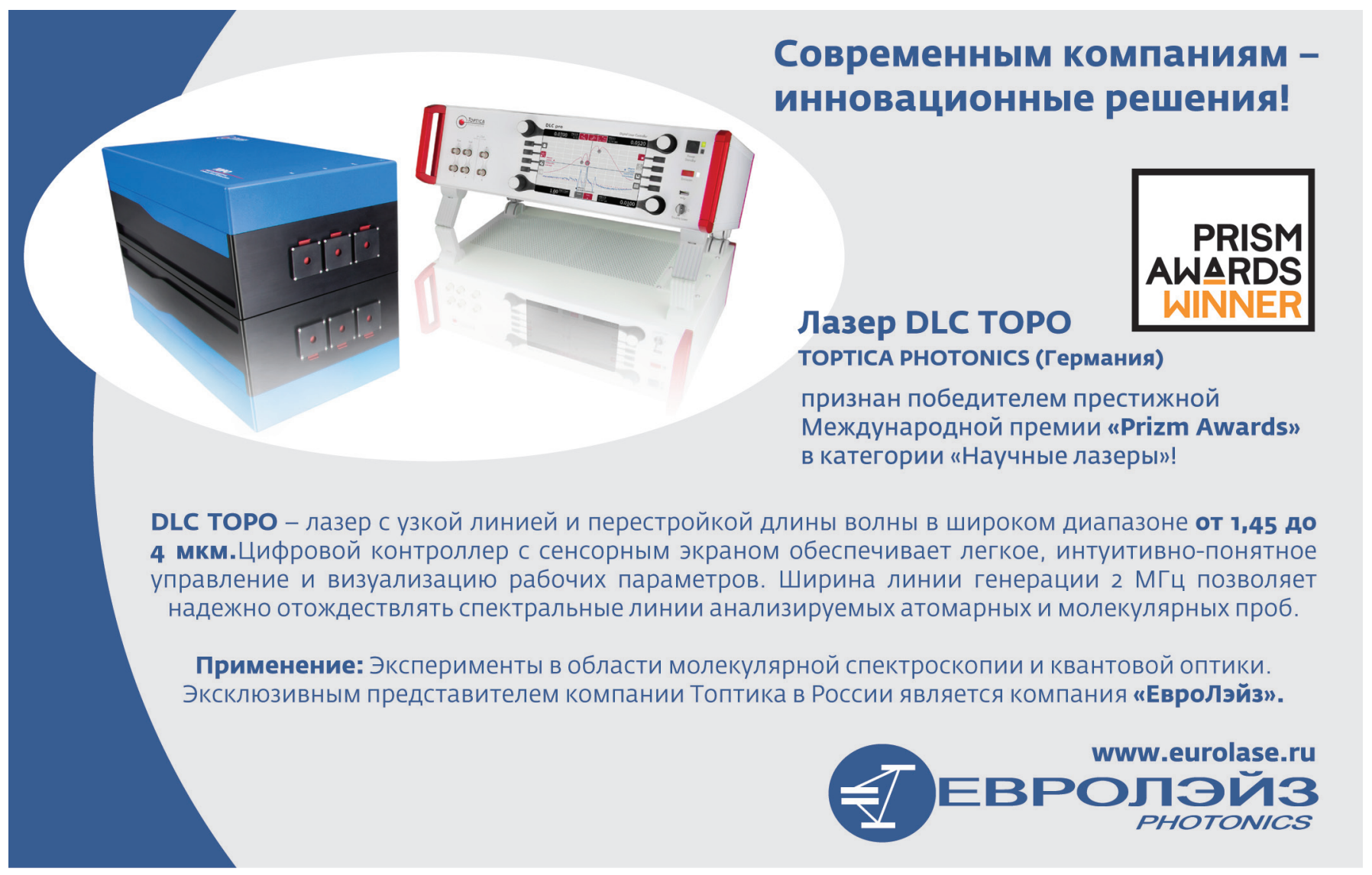




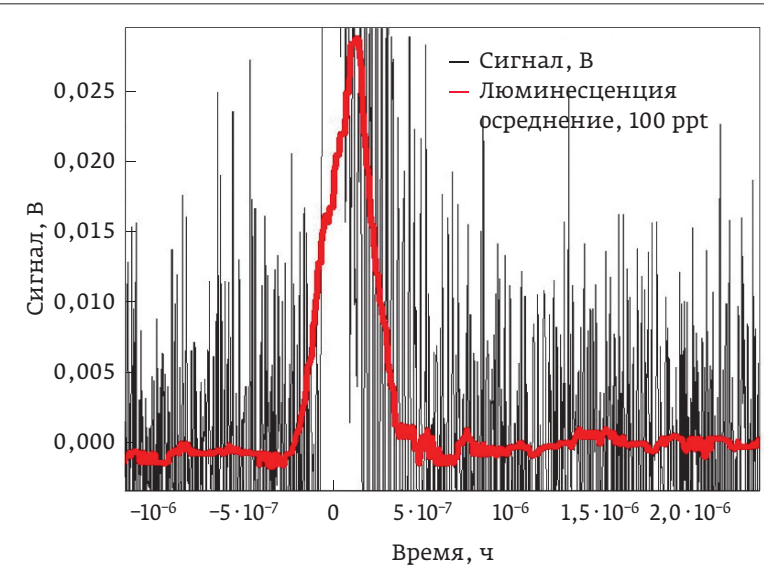

Puc. 11. Эффект пюминесценции в оптическом волокне, возникающий при импульсном гамма-излучении длительностью 20 нс и полученной дозой 22 Гр за импульс. Oптическая мощность в волокно не вводилась. Черным цветом приведен сигнал с фотоприемника, красной иинией-осреднение 100 Ги

ционном ускорителе электронов с длиной импульса 20 нс. Испытаны два идентичных образца одномодового изотропного волокна на длине волны 1310 нм (мощность 30 мкВт) при комнатной температуре (рис. 9). Первый образец получил дозу в импульсе 6 Гр. Чтобы достичь границу РНП 10 дБ/км, ему потребовалось около 4 мс. Через секунду образец восстановился до уровня потерь 0,45 дБ/км. Второй образец получил дозу 27 Гр и границу РНП в 10 дБ/км достиг за 7 мс. Через секунду релаксации РНП второго образца было равно 1 дБ/км. Таким образом, при разнице мощности дозы (и дозы в импульсе) до 4,5 раз РНП отличается примерно на 0,5 дБ/км через 1 с после воздействия [4].

Исследования на стойкость к воздействию импульсного нейтронного излучения показали (рис. 10), что РНП на длине волны 1550 нм составили 1,8 дБ/км через 0,2 с после воздействия длительностью 60 мкс с дозой 4 крад и флюенсом $1,5 \cdot 10^{13} \mathrm{H} / \mathrm{cm}^{-2}$.

\section{ЛЮМИНЕСЦЕНЦИЯ}

В работе [9] на основе серии опытов было выявлено, что люминесценция оптического волокна возникает при импульсном ионизирующем излучении при мощности дозы больше $10^{7} \mathrm{P} / \mathrm{c}$. Временная форма люминесценции, возникающей в волокне, повторяет форму гамма импульса. Волокна ОВ-РСИ125 были испытаны в подобных условиях на импульсном линейном индукционном ускорителе электронов с длиной импульса 20 нс. В образец волокна не вводилась оптическая мощность, детектирование сигнала производилось с помощью фотоприемника
Таблица. Геометрические и оптические параметры оптического волокна ОВ-РСИ125

\begin{tabular}{|c|c|c|}
\hline Параметр & \multicolumn{2}{|c|}{ Величина } \\
\hline Тип покрытия & акрилат & $\begin{array}{l}\text { углерод/ } \\
\text { полиимид }\end{array}$ \\
\hline Рабочая длина волны, мкм & \multicolumn{2}{|c|}{$1,31 / 1,55$} \\
\hline $\begin{array}{l}\text { Коэффициент затухания } \\
\text { на 1,31/1,55 мкм, дБ/ км }\end{array}$ & \multicolumn{2}{|c|}{$\leq 0,5 / \leq 0,6$} \\
\hline Числовая апертура & \multicolumn{2}{|c|}{$0,17 \pm 0,02$} \\
\hline $\begin{array}{l}\text { Диаметр модового поля } \\
\text { на длине волны 1,55 мкм, } \\
\text { мкм }\end{array}$ & \multicolumn{2}{|c|}{$8,6 \pm 0,6$} \\
\hline $\begin{array}{l}\text { Неконцентричность серд- } \\
\text { цевина / оболочка, мкм }\end{array}$ & \multicolumn{2}{|c|}{$\leq 0,7$} \\
\hline $\begin{array}{l}\text { Диаметр кварцевой обо- } \\
\text { лочки, мкм }\end{array}$ & \multicolumn{2}{|c|}{$125 \pm 2$} \\
\hline Пруф-тест,\% & $0,6 / 1,0 / 2,0$ & $0,6 / 1,0 / 2,0$ \\
\hline Строительная длина, км & \multicolumn{2}{|c|}{ до 10} \\
\hline Диаметр покрытия, мкм & $250 \pm 10$ & $155 \pm 5$ \\
\hline $\begin{array}{l}\text { Рабочий диапазон темпе- } \\
\text { ратур, }{ }^{\circ} \mathrm{C}\end{array}$ & От -55 до 85 & От -55 до 300 \\
\hline
\end{tabular}

с полосой пропускания 80 МГц и запоминающего осциллографа. На графике (рис. 11) представлен сигнал, связанный с люминесценцией, где по вертикальной оси отложено напряжение с фотоприемника в вольтах. Поглощенная доза 22 Гр за импульс длительностью 20 нс соответствует мощности дозы в $10^{9}$ Гр/с. Ширина кривой люминесценции на полувысоте составляет около 20 нс, что соответствует длительности импульса гамма-источника.

\section{ЗАКЛЮЧЕНИЕ}

Представленные в работе результаты подтверждают высокую стойкость к повышенной температуре эксплуатации, водородосодержащей среде, импульсному и непрерывному ионизирующему излучению оптического волокна ОВ-РСИ125, разработанного и производимого в ПАО ПНППК.

\section{ЛИТЕРАТУРА}

1. Kashaykin P. F. et al. Journal of Non-Crystalline Solids. 2019; 508: 26.

2. Tomashuk A. L. et al. Bulletin of the Lebedev Physics Institute. 2018; 45(12): 385.

3. Азанова И. С. et al. Фотон Экспресс. 2017; 6(142): 119. Azanova I. S. et al. Foton Ekspress. 2017; 6(142): 119.

4. Tomashuk A.L. et al. Pulsed-Bremsstrahlung-Radiation Effect on Undoped-and CeDoped-Silica-Core Optical Fibers at Wavelength of $1.55 \mu \mathrm{m}$. Lightwave Technology. 2016; PP(99): 1-1.

5. Kashaykin P.F. et al. Journal of Applied Physics. 2017; 121: 213104

6. Griscom D. L.Applied Physics letters. 1997; 71(2): 175.

7. Dianov E.M. et al. Soviet Journal of Quantum Electronics. 1979; 9(5): 636-637

8. Sigel G.H. IEEE Transactions on Nuclear Science. 1981; 28(6): 4095.

9. Андрияш А. В. Известия Челябинского научного центра. 2003; 4(21): 20. Andriyash A. V. Izvestiya Chelyabinskogo nauchnogo centra. 2003; 4(21): 20. 


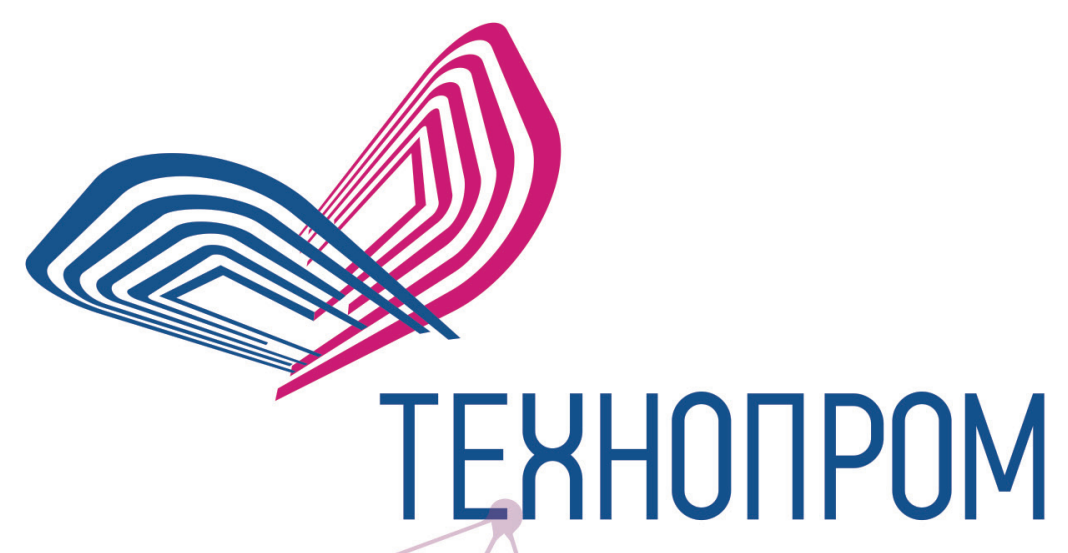

VII МЕЖДУНАРОДНЫЙ ФОРУМ И ВЫСТАВКА ТЕХНОЛОГИЧЕСКОГО РАЗВИТИЯ

«TЕХНОПРОМ-2019»

\section{8-20 СЕНТЯБРЯ 2019}

МВК «НОВОСИБИРСК ЭКСПОЦЕНТР»

Организатор Оператор

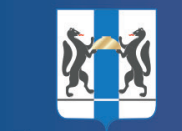

Правительство

Новосибирской области

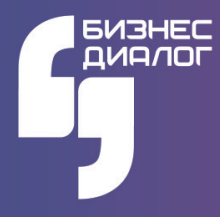

8(800)333-54-63 Звонок по России бесплатный forumtechnoprom.com 